\title{
Socio-Cultural Mobility as a Condition for Professional Activation of
}

\section{Shpektorenko Igor Valentinovich}

Doctor of Science in Public Administration, Professor, Professor of the Department of Public Administration and Local Self-Government of the Dnipropetrovsk Regional Institute of Public Administration, National Academy of Public Administration under the President of Ukraine

\section{Lysenko Olena Oleksiivna}

Postgraduate student of the Department of Public Administration and Local Self-Government of the Dnipropetrovsk Regional Institute of Public Administration, National Academy of Public Administration under the President of Ukraine

\section{Abstract}

We have identified the basic types of human mobility: social, professional, academic and some mixed types: socio-professional, professional-academic, socio-cultural, etc. Carryed out a comparative, comprehensive analysis, applying the method of sequential comparison of different interpretations of the concept of "socio-cultural mobility" with the use of systematic analysis, we substantiated the basic meaning of this concept: quality inherent in human (individual) which indicate a high level of social and cultural competence, social and general culture of the individual; the process of individual and group mobility of people in different socio-cultural environments (including professional environments in which a person operates), the process of realization of personal qualities, especially those that determine their ability to master social and cultural values and norms of a particular environment; achieved (or determined) result of activity, mobility in different socio-cultural environments (realized the potential of this type of human mobility for a certain period); criterion for evaluating activities in different socio-cultural environments, effectiveness, productivity, efficiency of the specified socio-cultural activities of man.

Keywords: socio-cultural mobility, condition, professional, activation, staff

\section{Introduction}

We emphasize that the socio-cultural mobility of a person develops in the social, and therefore - in the relevant professional and academic environments.

Socio-cultural mobility of the individual as a synthetic integrative quality of human is understood in broad and narrow meanings. In a broad sense, the concept of "socio-cultural mobility" is the quality of the individual to find and change socio-cultural position, status, to master new patterns of culture in different social, professional, academic and cultural environments. The narrow sense of the term "socio-cultural mobility" is the quality of human (individual), which is manifested in the acquisition of sufficient personal resources, social and cultural competence, personal, professional and academic culture, personal and professional 
experience. This in turn provides effectiveness of social and cultural activities relations, rapid mastery of values, norms within one or more cultures or subcultures (stratum of society, profession, government, institution, organization, etc.).

From the scientific and practical view, the activity (operational, role, process) expression of human socio-cultural mobility is of special relevance. A broad understanding of the concept of "socio-cultural mobility" will include the ability, willingness and ability of a person to carry out their own activities in a fairly broad context, to acquire new competencies (social, cultural, individual, personal, and professional etc.) not only in one specific cultural environment, but also in the conditions of intercultural movements of the person (intercultural type of cultural mobility), or activity of the person in the conditions of multiculturalism and in the conditions of difficult social and cultural stratification of a society. Conditionally that is a multicultural person that able to operate in a wide range of social and cultural environments. Thus, the expression of socio-cultural mobility from a theoretical view should be broader, and go beyond the activity expression of the concept of "social culture", which traditionally refers to the integrated characteristics inherent in people as a rule of one particular society and culture.

The activity aspect of socio-cultural mobility presupposes its understanding in certain activity aspects, namely, in indicators, characteristics, attributes, signs of activity. We are talking, in other words, about the role interpretation of socio-cultural mobility. In such interpretations of cultural mobility can be found those internal and external factors, different conditions, visible and latent processes, which ultimately must ensure the sustainable formation of sociocultural mobility of human in certain social, sociocultural, professional, organizational and other conditions, in a certain social, cultural, academic, professional space or environment. In essence, a somewhat narrowed aspect of the "style of activity" (its socio-cultural aspect) is studied, which, from our point of view, will not always be subject to algorithmization and modeling.

The functional structure of socio-cultural mobility of the employee can be represented as follows: socio-cultural mobility of a person in relation to the use of ascending materials, norms, standards, tools, approaches and methods of applying these tools, final results, ways of transition of ascending materials, norms and standards to the final product social, sociocultural, professional, academic and other activities; socio-cultural mobility of a person (activity, process, role aspect of socio-cultural mobility with a focus on the result of activity). In the last sense, the concept under consideration, the most realized activating aspect (function) of socio-cultural mobility of the individual as its quality which is realized as a social, cultural competence only in activities.

Using some approaches of O. L. Emelyanov [1], we note that socio-cultural mobility of man can be further divided into elements: socio-cultural mobility in terms of understanding and acceptance of the content of values, norms of activities (goals, plans, programs, content of functions and tasks, technologies, methods, approaches, means, etc.) and socio-cultural mobility in relation to the presence of a person, from our position, a set of value-oriented and competency qualities in a person: abilities required (semantic, essential and activating aspect of socio-cultural mobility (structure of socio-cultural mobility of a person).

Substructure 1 of this structure is defined by us on the basis of structural and structuralfunctional analysis and functional-procedural purpose of social, cultural, socio-cultural, professional, academic and other environments, using methods: system analysis, structuralfunctional, expert-analytical, decomposition, parametric, modeling, structuring goals. 
Substructure 1 of the structure of socio-cultural mobility consists of the functions of the sociocultural environment, which are determined by the relevant objective factors (factors) necessary to maintain and develop socio-cultural mobility of people: socio-cultural orientation (formation of internal picture, worldview, internally consistent norms, values, preferences, etc.), norms (standards) of culture (socially approved behavior); socio-cultural adaptation, socio-cultural motivation, socio-cultural activation, socio-cultural education (training) and education. These are objective factors of socio-cultural mobility of people.

The first group of substructure 2 includes qualities that have a value-oriented nature and belong to the internal psycho-emotional, motivational, value-motivational areas: sociocultural interests, intentions, expectations, socio-cultural orientation of the person, sociocultural suitability, satisfaction with the social and cultural aspects of life.

Another group of substructure 2 consists of competency qualities, which, interacting with value-oriented, undoubtedly affect in the formation of social and cultural competencies and influencing the professionalism and various types of human mobility mentioned above. These are: innate abilities and acquired abilities; professional culture (cultural mobility); professional learning (academic mobility); social and cultural competence; socio-cultural experience. Value-oriented and competence qualities are subjective factors (factors) of sociocultural mobility, they develop the internal needs of the individual in this type of mobility, and their formation takes place in close interaction with each other.

It is established that certain objective and subjective factors provide a systematic understanding of the impact of internal and external factors on a person in the process of his socio-cultural and professional development. They are activators of human activity in any field. These factors (activators) determine the quality, content, directions of formation, the results of the process not only socio-cultural but also professional development and development of the individual. The characteristics of the elements of the structure of sociocultural mobility of people, including those involved in professional and academic (educational) activities indicate that each of them acts either as a certain internal process, as the purpose, result and quality of the process.

\section{Literature}

[1] Emelyanov A. L. Level's typology of professionalism of civil servants / A. L. Emelyanov [El. resource]. - Access mode: http://mmpk1.narod.ru/tugs.htm. 